\title{
Electron density profiles of the topside ionosphere
}

\author{
Xueqin Huang $\left({ }^{1}\right)$, Bodo W. Reinisch $\left({ }^{1}\right)$, Dieter Bilitza $\left({ }^{2}\right)$ and Robert F. Benson $\left({ }^{3}\right)$ \\ $\left.{ }^{1}{ }^{1}\right)$ Center for Atmospheric Research, University of Massachusetts Lowell, MA, U.S.A. \\ $\left(^{2}\right)$ Raytheon ITSS, GSFC, Code 632, Greenbelt, MD, U.S.A. \\ $\left(^{3}\right)$ GSFC, Code 692, Greenbelt, MD, U.S.A.
}

\begin{abstract}
The existing uncertainties about the electron density profiles in the topside ionosphere, i.e., in the height region from $h_{m} F_{2}$ to $\sim 2000 \mathrm{~km}$, require the search for new data sources. The ISIS and Alouette topside sounder satellites from the sixties to the eighties recorded millions of ionograms but most were not analyzed in terms of electron density profiles. In recent years an effort started to digitize the analog recordings to prepare the ionograms for computerized analysis. As of November 2001 about 350000 ionograms have been digitized from the original 7-track analog tapes. These data are available in binary and CDF format from the anonymous ftp site of the National Space Science Data Center. A search site and browse capabilities on CDAWeb assist the scientific usage of these data. All information and access links can be found at http://nssdc.gsfc.nasa.gov/space/isis/isisstatus.html. This paper describes the ISIS data restoration effort and shows how the digital ionograms are automatically processed into electron density profiles from satellite orbit altitude (1400 km for ISIS-2) down to the $F$ peak. Because of the large volume of data an automated processing algorithm is imperative. The TOPside Ionogram Scaler with True height algorithm TOPIST software developed for this task is successfully scaling $\sim 70 \%$ of the ionograms. An «editing process» is available to manually scale the more difficult ionograms. The automated processing of the digitized ISIS ionograms is now underway, producing a much-needed database of topside electron density profiles for ionospheric modeling covering more than one solar cycle.
\end{abstract}

Key words electron density profile - topside ionosphere - ionogram processing

\section{Introduction}

Modeling of the topside ionosphere (from the $F$ peak to about $2000 \mathrm{~km}$ ) suffers from a scarcity of data because ground-based ionosondes only probe up to the $F$-peak. Satellite-borne sounders provided information about the topside ionosphere. But only a small percentage of these

Mailing address: Prof. Bodo W. Reinisch, Center for Atmospheric Research, University of Massachusetts Lowell, 600 Suffolk St., Lowell, MA 01854, U.S.A.; e-mail: Bodo_Reinisch@uml.edu data have been processed into electron density profiles, which is the parameter of greatest interest for topside modeling.

An ionosonde transmits signals sweeping through a typical frequency range and records the time delay it takes the signal to be reflected back to the receiver. The ionogram established in this way usually consists of an ordinary and extraordinary trace (O- and $\mathrm{X}$-trace). Ionogram analysis includes finding these traces and then inverting them into an electron density profile. The problem of the topside sounder missions in the sixties and seventies and the reason for the low percentage of obtained electron density profiles is the fact that the scaling had to be done manually. In the eighties and nineties, automated scaling and inversion algorithms were developed 
and perfected (Huang and Reinisch, 1982) and are now well-established tools of space weather observations with ground-based ionosondes (Reinisch et al., 2001; Huang and Reinisch, 2001). This paper describes an effort to apply these automated scaling and inversion routines to the large database established by the U.S./ Canadian Alouette and ISIS topside sounders.

The Alouette-1, -2 and ISIS-1, -2 satellites were the first satellites that were equipped with topside sounder instruments to monitor the topside ionosphere from the satellite orbit altitude down to the $F$-peak. The launch dates and orbit parameters are listed in table I. ISIS 1 launched in 1969 and ISIS 2 launched in 1971 were operated by NASA until 1979, then by CRC (Canada) until 1984, and finally by RRL (Japan) until 1990. Additional instruments carried by these satellites included VLFreceivers, Energetic Particle Detectors (EPD), Ion Mass Spectrometers (IMS), Retarding Potential Analyzers (RPA) and Photometers. These satellites either had limited onboard recording capabilities (ISIS) or none at all (Alouette). Data were therefore primarily recorded within the viewing area of several telemetry down-link stations. Because of the great interest in these data many nations participated in the Alouette/ISIS program and provided dedicated telemetry stations. Table II lists 24 of these stations illustrating their global distribution. A number of additional stations operated at various times, but these 24 are the ones considered in our data restoration effort. Several institutions were also involved in data reduction efforts to obtain electron density profiles from manually scaled ionograms. Of the close to a million ionograms recorded by the Alouette/ISIS satellites several tens of percent are stored on more than 12000 rolls of $35 \mathrm{~mm}$ microfilm at the National Space Science Data Center (NSSDC). Only a few percent of the ionograms were processed into electron density profiles. About 150000 profiles were submitted to NSSDC's archives and are now available online from NSSDC's anonymous ftp site at ftp://nssdcftp.gsfc.nasa.gov/.

This is also the story of a successful data restoration effort that saved a considerable portion of an irreplaceable data set from the brink of extermination. The Alouette and ISIS telemetry data were stored on more than 100000 7-track tapes in the Canadian Public Archives (CPA). In the early nineties the CPA indicated its intent to discard these tapes because of storage space and cost limitations and the dormant state of these data. With help from G. James (CRC, Ottawa) and with funding from NASA/OSS/ AISRP, R. Benson managed to save about 18000 of these tapes (specifically selected for time and location; see next section) and ship about 14000 to the Goddard Space Flight Center (GSFC) for processing and analysis. The rest of the telemetry tapes was discarded and the information contained on them is now lost.

\section{Digitization of ISIS ionograms}

At GSFC the analog topside sounder recordings from the 7-track tapes were digitized and made available online through NSSDC's anonymous ftp archive. Before this, however, the important first step in this data restoration effort was the selection of desirable tapes, because it became clear that it was feasible to only save about $10-20 \%$ of the tape total. The tapes were selected in order to obtain global coverage and to accommodate special requests that address subjects and time periods of particular interest.

Table I. ISIS- 1 and -2 orbit parameters.

\begin{tabular}{cccc}
\hline \hline Satellite & Launch date & Height range/km & Inclination/degree \\
\hline Alouette 1 & $1962-09-29$ & 1000 & 80 \\
Alouette 2 & $1965-11-29$ & $500-3000$ & 80 \\
ISIS 1 & $1969-01-30$ & $550-3500$ & 88 \\
ISIS 2 & $1971-04-01$ & 1400 & 88 \\
\hline
\end{tabular}


Table II. The 24 ground stations for which tapes were selected; for each of the four satellites the number of tapes is shown and in brackets the years covered.

\begin{tabular}{|c|c|c|c|c|c|c|c|}
\hline Location & Station ID & Lat. & Long. & Al- 1 & Al-2 & ISIS-1 & ISIS-2 \\
\hline Resolute Bay, Canada & RES & 75 & 265 & & & $327(76)$ & $504(73-79)$ \\
\hline Tromso, Norway & TRO, TRM & 70 & 19 & & & 320 & $141(73-76)$ \\
\hline Sodankyla, Finland & SOD & 67 & 27 & & & & $63(77-79)$ \\
\hline Fairbanks, Alaska & ULA & 65 & 212 & $1(62)$ & & $244(73-79)$ & $439(73-79)$ \\
\hline Winkfield, U.K. & WNK & 51 & 359 & & $2(66)$ & 319 & $405(73-79)$ \\
\hline Ottawa, Canada & OTT & 45 & 284 & & & $1187(69-83)$ & $991(73-83)$ \\
\hline Kashima, Japan & $\mathrm{KSH}$ & 36 & 141 & & & $103(78-81)$ & $879(73-79)$ \\
\hline $\begin{array}{l}\text { Las Palmas Canary } \\
\text { Island, Spain }\end{array}$ & $\mathrm{CAN}$ & 28 & 345 & & & & $106(74-75)$ \\
\hline Ahmedabad, India & AME & 23 & 73 & & & & $265(73-77)$ \\
\hline $\begin{array}{l}\text { Ouagadougou, Burkina } \\
\text { Faso }\end{array}$ & ODG & 14 & 359 & & & 745 (73-?) & $214(73-75)$ \\
\hline $\begin{array}{l}\text { Kwajalein, Marshall } \\
\text { Islands }\end{array}$ & KWA & 9 & 168 & & & & 140 \\
\hline $\begin{array}{l}\text { Kourou, French } \\
\text { Guyana }\end{array}$ & KRU & 5 & 307 & & & & $212(74-77)$ \\
\hline Quito, Equador & QUI & -1 & 281 & $1(62)$ & 700 & $483(69-72)$ & $366(73-79)$ \\
\hline Brazzaville, Congo & $\mathrm{BRZ}, \mathrm{BZV}$ & -4 & 15 & & & & $34(73-74)$ \\
\hline Ascension Island, U.K. & $\mathrm{CAN}$ & -8 & 346 & & & & $174(75-77)$ \\
\hline Lima, Peru & LIM & -12 & 283 & & 11 & & \\
\hline $\begin{array}{l}\text { Johannesburg, } \\
\text { South Africa }\end{array}$ & BUR, JOB & -26 & 28 & & & & $192(73-75)$ \\
\hline Santiago, Chile & SNT, AGO & -33 & 298 & & 428 & $209(69)$ & $240(73-76)$ \\
\hline Orroral, Australia & ORR & -36 & 149 & & & $66(72-?)$ & $232(73-78)$ \\
\hline Lauder, New Zealand & $\mathrm{LAU}$ & -45 & 170 & & & & $604(73-80)$ \\
\hline $\begin{array}{l}\text { Kerguelen Islands, } \\
\text { France }\end{array}$ & KER & -49 & 70 & & & $98(81-83)$ & $464(77-83)$ \\
\hline Falkland Island, U.K. & SOL & -52 & 302 & & 421 & & $45(72)$ \\
\hline $\begin{array}{l}\text { Terre Adelie, } \\
\text { Antarctica }\end{array}$ & $\mathrm{ADL}$ & -67 & 140 & & & $54(82-83)$ & $738(73-83)$ \\
\hline $\begin{array}{l}\text { Syowa Base, } \\
\text { Antarctica }\end{array}$ & $\mathrm{SYO}$ & -69 & 40 & & & & $241(78-82)$ \\
\hline
\end{tabular}

The selection included data from 24 telemetry stations from the years 1972-1984. Table II provides some of the specifics in terms of the number of tapes from a specific satellite and stations and the years covered. In selecting these tapes we also considered the time periods already covered by NSSDC's data holdings. Typically, 80-100 tapes/year were specified centered on each of the equinoxes and solstices. About 8000 tapes were selected with special emphasis on time periods coinciding with the DE satellites and from stations close to the magnetic equator, an area not so well covered by the existing data sets.

The digitization at GSFC's Data Evaluation Laboratory (DEL) was performed using an A/D converter and software device driver compatible with the OS/2 operating system used by a 486based Programmable Telemetry Processor (PTP). The digitized sounder data consist of 8-bit receiver-amplitude values collected at a 40 $\mathrm{kHz}$ rate and contain the time and the frequency 
associated with each sounder pulse. The data are provided in full and average ( 4 consecutive range bins averaged to yield one amplitude sample) in OS2 binary format; the average resolution data were also converted to CDF format at NSSDC. The virtual range resolution is $3.75 \mathrm{~km}$ for the full resolution ionograms and $15 \mathrm{~km}$ for the average resolution data.

As of November 2001 about 350000 ionograms have been digitized. A small selection of these data has also been made available for plotting and browsing on CDAWeb (http:// cdaweb.gsfc.nasa.gov/). Other services available from the ISIS homepage include a search page for locating ionograms for specific times, locations, and other search criteria and software for an interactive IDL interface for plotting, scaling, and inverting the ionograms based on the inversion program of Jackson (1969).

\section{TOPIST description}

Our goal was to automatically deduce the electron density profiles from the digitized ionograms. This is the logical next step after the digitization process since topside electron densities are one of the most important data

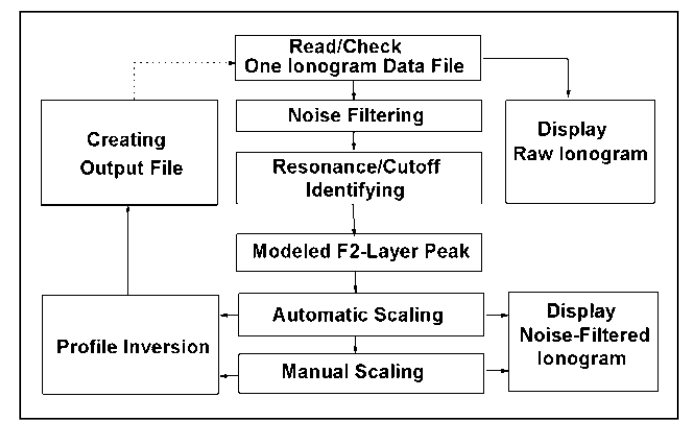

Fig. 1. Flow chart of TOPIST.

products derived from ionograms. This requires locating and identifying the echo traces on the ionogram and then applying an inversion algorithm that inverts the echo traces into an electron density profile. Because of the large volume of ionograms this has to be done automatically in order to provide the maximum input to ionospheric models. Our first project step was therefore the development of a computer program for the automated tracing and inversion of topside ionograms. A TOPside Ionogram Scaler with True height algorithm (TOPIST) program has been developed that is

Table III. Processing functions in TOPIST.

\begin{tabular}{ll}
\hline \hline \multicolumn{1}{c}{ Process } & \multicolumn{1}{c}{ Method } \\
\hline Reading ionogram file & Full or average ionogram/OS2 binary. \\
\hline Noise filter & $\begin{array}{l}\text { Individual threshold for each frequency. Most probable amplitude at low ranges } \\
\text { and at large ranges is determined. Smaller value is selected as nominal threshold. }\end{array}$ \\
\hline $\begin{array}{l}\text { Search for resonance } \\
\text { frequencies }\end{array}$ & $\begin{array}{l}\text { 5-frequency comb with } f_{N} \text { as free variable slides along frequency axis in search } \\
\text { for maximum amplitude. }\end{array}$ \\
\hline $\begin{array}{l}\text { Consult model } F_{2} \\
\text { peak parameters }\end{array}$ & $\begin{array}{l}f_{0} F_{2} \text { and } h_{m} F_{2} \text { values are calculated from URSI and CCIR coefficients and used } \\
\text { as guide for the auto-scaling. If ground echo traces are observed, they also are } \\
\text { used in the } f_{0} F_{2} \text { search. }\end{array}$ \\
\hline Trace scaling & $\begin{array}{l}\text { Find potential trace points for each frequency line storing their amplitude and } \\
\text { connection length to neighbors. Find optimal combination of resonance } \\
\text { frequencies and O- and X-traces using a family of generic functions. }\end{array}$ \\
\hline $\begin{array}{l}\text { Electron density } \\
\text { profile calculation }\end{array}$ & $\begin{array}{l}\text { Introduce a reduced frequency variable and represent profile with } \\
\text { Chebyshev polynomials. Inversion can work with O-trace only, or X-trace } \\
\text { only, or both traces and possibly the Z-trace. }\end{array}$ \\
\hline
\end{tabular}


successfully scaling $\sim 70 \%$ of the ionograms. The TOPIST software also includes an «editing option» (called Manual Scaling in fig. 1) for the manual scaling of the more difficult ionograms, which could not be scaled during the automated TOPIST run.

The most difficult part of the task is the automatic scaling of the echo traces. Unlike the ionograms from modern ionosondes (Reinisch, 1996) the ISIS ionograms do not identify the wave polarization of the different echo traces, so physical logic must be applied to identify the $\mathrm{O}$ and/or $\mathrm{X}$ traces, and this is not always successful. Characteristic resonance features seen in the topside ionograms include those at the gyro and plasma frequencies. An elaborate scheme was developed to automatically identify these resonance frequencies in order to determine the local plasma and gyro frequencies.
This information helps in the identification of the $\mathrm{O}$ and $\mathrm{X}$ traces, and it provides the starting density of the electron density profile. The inversion of the echo traces into electron density profiles uses the same modified Chebyshev polynomial fitting technique that is successfully applied in the analysis of topside ionograms and ground-based Digisonde ionograms (Huang and Reinisch, 1982; Reinisch and Huang, 1983).

\section{Processing procedures}

The flowchart in fig. 1 and table III describe the individual steps that TOPIST takes to analyze the ionograms. The TOPIST opening window (fig. 2) allows one to specify the processing parameters. The performance characteristics of TOPIST are summarized in table IV.

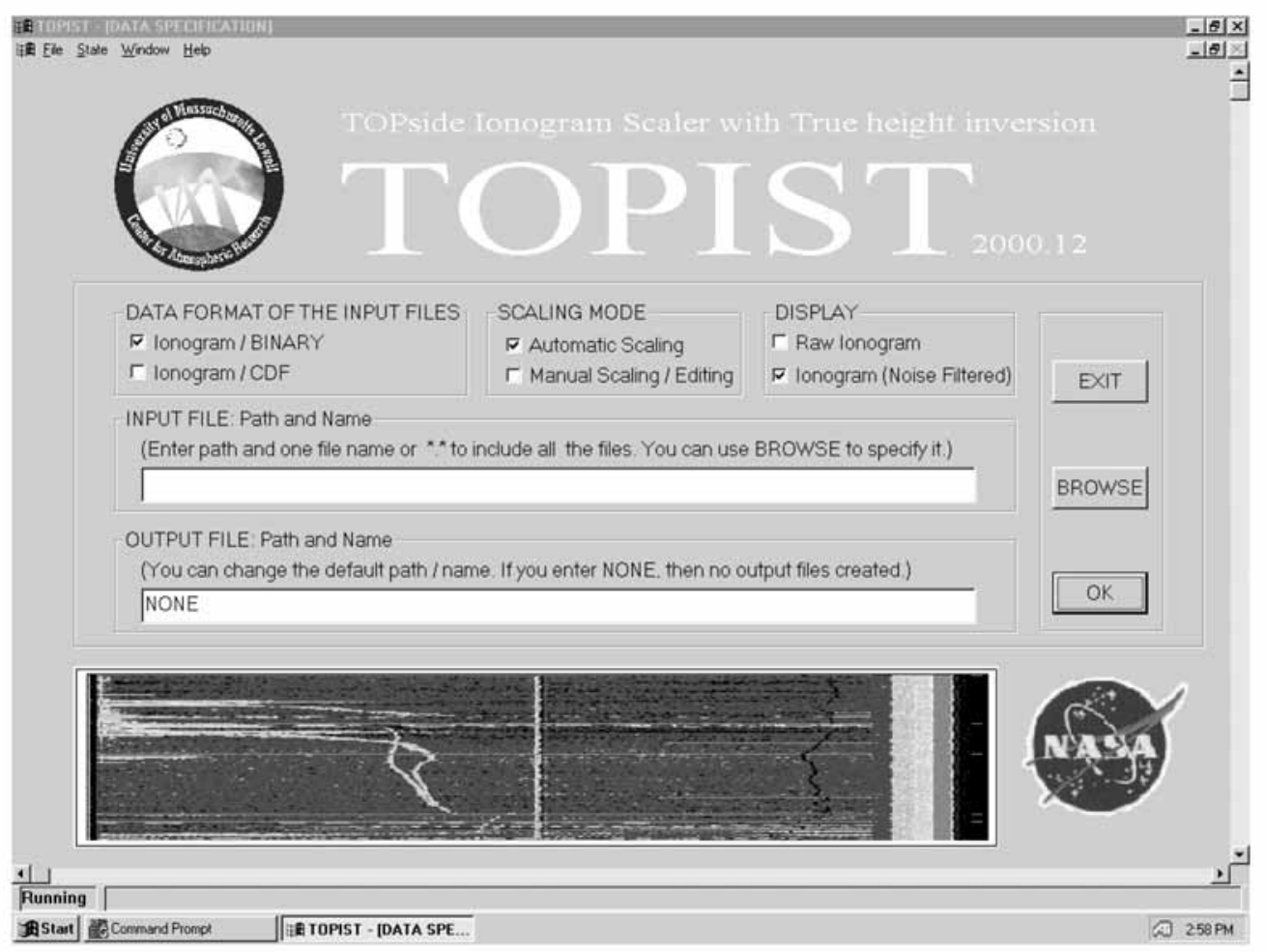

Fig. 2. TOPIST opening window. 
Table IV. TOPIST performance.

\begin{tabular}{ll}
\hline \hline \multicolumn{1}{c}{ Function } & \multicolumn{1}{c}{ Description } \\
\hline Test database & $\sim 800$ digitized ISIS-2 ionograms \\
Success rate & $70 \%$ of manually scalable ionograms are successfully auto-scaled \\
Auto-scaling failures & Scaling errors occur during severe spread; when data are missing in a large \\
& frequency interval; in the presence of unidentified traces (oblique?); \\
& when resonance frequencies are incorrectly identified \\
\hline
\end{tabular}

\section{Summary and discussion}

A considerable amount of a very valuable data source for the topside ionosphere has been saved in a last minute effort. Close to 340000 topside ionograms have so far been digitized and this process continues at a rate of about 6000 per month. A software algorithm (TOPIST) was developed for automated scaling and inversion of ionograms and is now successfully scaling about $70 \%$ of the digitized ionograms. The resulting topside electron density profiles are being made available online from NSSDC's anonymous ftp archive (nssdcftp.gsfc.nasa.gov).

This unique new data source for modeling the topside electron density will more than triple the amount of electron density data previously available from the Alouette and ISIS satellites, and it will greatly extend the solar cycle coverage of the combined Alouette/ISIS database. A better representation of conditions during very high solar activity is especially important because the largest topside electron densities are found during these time periods and, as a result, the strongest space weather effects occur during such intervals. For real time space weather monitoring future topside sounders should provide for automatic scaling of the ionograms as proposed by Reinisch et al. (2001).

The data set will also help special investigation that were considered in selecting the original telemetry tapes, e.g., combining ISIS data with coincident DE data, the investigation of sounder-stimulated plasma resonances, and studies of high latitude and low latitude plasma processes. The importance of these new digital data was recently demonstrated by Benson and Grebowsky (2001). They produced several orbitplane electron-density contours through the winter, nighttime polar cap ionosphere during solar minimum. Their observations, combined with other data, suggest that an absence of an $F$-layer ionization peak may be a frequent occurrence at high latitudes.

\section{Acknowledgements}

This work was supported through NASA/ OSS Applied Systems and Information Research Program (ASIRP) Grant NAG5-8145. We are grateful to W.B. Schar of Emergent/GSFC for his key role in producing the ISIS digital ionograms and transferring them to the NSSDC under AISRP RTOP Grant \# 370-03-00-04 at GSFC.

\section{REFERENCES}

BENSON, R.F. and J.M. GREBOWSKY (2001): Extremely low ionospheric peak altitudes in the polar hole region, Radio Sci., 36, 277-285.

HuANG, X. and B.W. REINISCH (1982): Automatic calculation of electron density profiles from digital ionograms. 2. True height inversion of topside ionograms with the profile-fitting method, Radio Sci., 17 (4), 837-844.

HuANG, X. and B.W. ReINISCH (2001): Vertical electron content from ionograms in real time, Radio Sci., 36 (2), 335-342.

JACKSON, J.E. (1969): The reduction of topside ionograms to electron-density profiles, Proc. IEEE, 57 (6), 960-976.

REINISCH, B.W. and X. HUANG (1983): Automatic calculation of electron density profiles from digital ionograms. 3. Processing of bottomside ionograms, Radio Sci., 18 (3), 477-492.

REINISCH, B.W. (1996): Modern Ionosondes, Modern Ionospheric Science, edited by H. KOHL, R. RUSTER and K. SCHLEGEL, European Geophysical Society, 37191 Katlenburg-Lindau, Germany, 440-458.

REINISCH, B.W., D.M. HAINES, G.S. SALES, R.F. BENSON, J.L. GREEN and W.W.L. TAYLOR (2001): Radio sounding in space: magnetosphere and topside ionosphere, J. Atmos. Sol.-Terr. Phys., 63, 87-98. 